\title{
Implantable cardioverter defibrillator as a treatment for massive left ventricular fibroma-induced ventricular arrhythmia in a child
}

\author{
In Su Choi ${ }^{1}$, Hyung Ki Jeong ${ }^{2}$, Hyung Wook Park², Yi-Seul Kim \\ 'Department of Pediatrics, Chonnam National University Children's Hospital, Gwangju; ${ }^{2}$ Department of Cardiovascular Medicine, Chonnam National \\ University Hospital, Gwangju, Korea
}

Pediatric cardiac tumors are rare. Among these, cardiac fibroma is the second most common. Its clinical manifestations depend on size and location of the tumor and include arrhythmia or obstruction to blood flow. Symptomatic cardiac fibroma is generally treated with surgical resection or cardiac transplantation. We present the case of a 12-year-old boy with a lethal ventricular arrhythmia induced by a remnant tumor that was previously partially resected. An implantable cardioverter defibrillator was inserted as the arrhythmia was resistant to medical treatment. He was discharged in stable condition with an implantable cardioverter defibrillator generator and followed up in the outpatient clinic.

Key Words: defibrillator; fibroma; implantable; tachycardia, ventricular

Cardiac tumors in the pediatric age group are rare. Among these, cardiac fibroma is the second most common tumor after rhabdomyoma. Most cases are reported in utero or in infants. Fibromas consist of fibroblasts, collagen fibers, and minimal elastic tissues. Although fibromas are histologically benign, they can be symptomatic, causing arrhythmia, inflow and outflow tract obstruction of blood flow, coronary artery compromise, and thromboembolic events. The signs and symptoms depend on the size and location of the tumor [1].

Cardiac fibromas involving the interventricular septum frequently induce conduction system disease and result in rhythm abnormalities. Patients with such cardiac fibromas have a high incidence of ventricular arrhythmias, often from a young age. Sudden death from ventricular arrhythmia has been reported in $23 \%$ of cases [2]. We present the case of a 12-yearold boy with a cardiac fibroma that caused ventricular arrhythmia.

\section{CASE REPORT}

A 12-year-old boy who experienced a cardiac arrest was referred to our emergency department from a local hospital in January 2020. His medical history revealed a cardiac fibroma that was detected prenatally. After birth, the fibroma was partially resected twice at another hospital, as the size and extent of the tumor prohibited single-stage resection. Heart transplantation was considered at the time. At the age of 2 years, he experienced cardiac arrest

\section{Case Report}

Received: May 21, 2020

Revised: July 15, 2020

Accepted: July 23, 2020

Corresponding author Yi-Seul Kim

Department of Pediatrics, Chonnam National University Children's Hospital, 42 Jebong-ro, Dong-gu, Gwangju 61469, Korea Tel: +82-62-220-6647 Fax: +82-62-222-6103 E-mail:nadltmf@naver.com

Copyright (@) 2021 The Korean Society of Critical Care Medicine

This is an Open Access article distributed under the terms of Creative Attributions Non-Commercial License (https:// creativecommons.org/li-censes/by-nc/4.0/) which permits unrestricted noncommercial use, distribution, and reproduction in any medium, provided the original work is properly cited. 
and was admitted to the same hospital. At that time, ventricular tachycardia was repeatedly detected. He developed central nervous system complications, including hypoxic-ischemic encephalopathy and quadriplegia, after which he had received oral amiodarone. Later, hydrocephalus was detected on brain magnetic resonance imaging, and he was treated with a ventriculo-peritoneal shunt.

The patient's medication was discretionally discontinued at 10 years of age. At 12 years of age, he experienced a cyanotic spell at home and was unable to breathe. He received cardiopulmonary resuscitation from his father. When the rescue squad arrived, they determined that he was in ventricular fibrillation. Defibrillation was performed, and sinus rhythm was restored. The boy was transported to a local hospital where he received endotracheal intubation. Thereafter, he was referred to our hospital, where he was admitted to the pediatric intensive care unit.

On admission, the patient's blood pressure and heart rate were 115/70 mm Hg and 151 beats per minute, respectively. He was intubated and was in a stuporous state. Cardiac murmurs were not heard on chest auscultation. Venous blood gas analysis revealed $\mathrm{pH}, 7.22 ; \mathrm{pCO}_{2}, 58 \mathrm{~mm} \mathrm{Hg}$; $\mathrm{pO}_{2}, 28 \mathrm{~mm} \mathrm{Hg}$; $\mathrm{HCO}_{3}, 18.9 \mathrm{mmol} / \mathrm{L}$; and $\mathrm{SvO}_{2}, 39 \%$. Serum biochemical analysis showed a lactate level of $9.25 \mathrm{mmol} / \mathrm{L}$. The levels of serum electrolytes were as follows: sodium, $142 \mathrm{mEq} / \mathrm{L}$; potassium, $3.6 \mathrm{mEq} / \mathrm{L}$; chloride, $109 \mathrm{mEq} / \mathrm{L}$; total calcium, $8.4 \mathrm{mEq} / \mathrm{L}$;

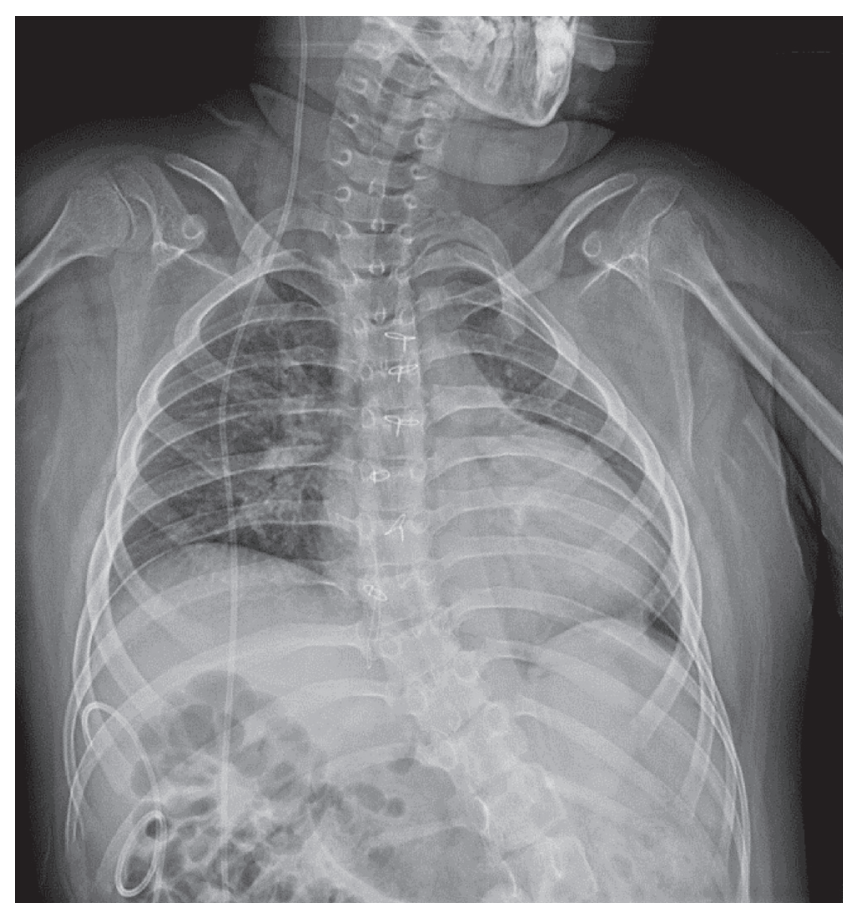

Figure 1. Chest radiograph showing cardiomegaly (cardiothoracic ratio, 0.55). ionized calcium, $2.3 \mathrm{mEq} / \mathrm{L}$; inorganic phosphorous, $4.0 \mathrm{mg} / \mathrm{dL}$; and magnesium, $1.7 \mathrm{mg} / \mathrm{dL}$. Serum cardiac enzyme levels were as follows: creatine kinase, $155 \mathrm{IU} / \mathrm{L}$; creatine kinase-MB, 3.37 $\mathrm{ng} / \mathrm{mL}$; troponin-T, $0.137 \mathrm{ng} / \mathrm{mL}$; and pro-brain natriuretic peptide, $85.9 \mathrm{pg} / \mathrm{ml}$. Cardiomegaly was observed on chest radiography (Figure 1). Electrocardiogram showed sinus tachycardia with intermittent monomorphic ventricular premature contractions (VPCs). On the 1st day of hospitalization, the patient was supported by mechanical ventilation, without an intravenous inotropic agent. On the 2nd day, VPCs preceded abrupt ventricular fibrillation. He was resuscitated with sinus rhythm restoration following cardiopulmonary resuscitation and defibrillation (2 J/kg). Transthoracic echocardiography (Figure 2) and cardiac computed tomography (Figure 3) demonstrated a known fibroma (about $9.5 \mathrm{~cm} \times 5.5 \mathrm{~cm}$ ) in the anteroseptal wall of the left ventricle without blood flow obstruction. Soon after, he developed ventricular tachycardia (Figure 4), and direct current cardioversion was performed along with intravenous amiodarone administration. Additionally, intravenous dopamine was administered for hypotension management. From the third to 9th days of hospitalization, he experience recurrent ventricular tachycardia refractory to multiple (45 times) direct current cardioversions ( 2 to $4 \mathrm{~J} / \mathrm{kg}$ ) and aggressive administration of antiarrhythmic agents (intravenous amiodarone and lidocaine). Although we suspected that the fibroma induced the arrhythmia, we believed additional partial resection of the tumor would not prevent it. Further, the patient's poor neurocognitive and psychomotor states posed additional considerations for management. On the 10th day of hospitalization, he underwent an electrophysiology study, and a single-chamber implantable cardioverter defibrillator

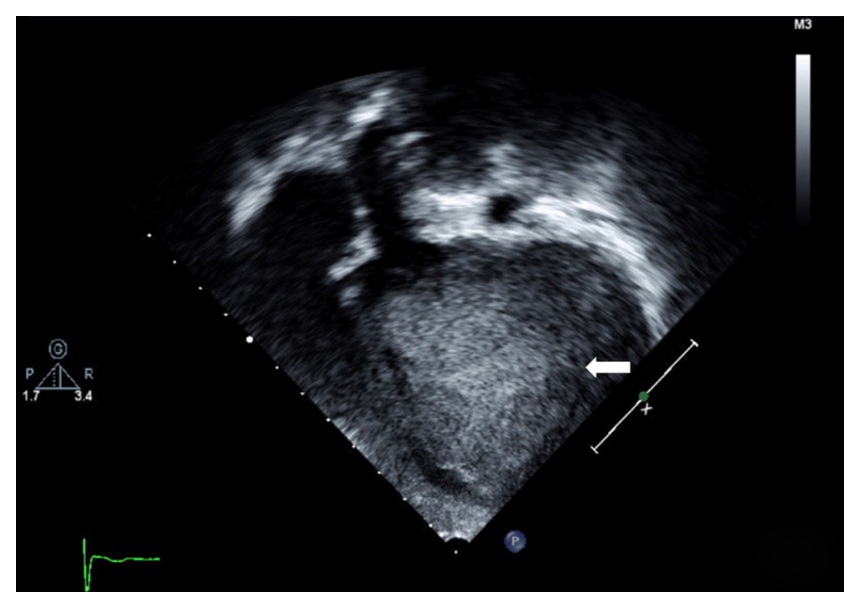

Figure 2. Two-dimensional echocardiogram in four-chamber view showing a mass in left ventricle anteroseptal wall (white arrow). 


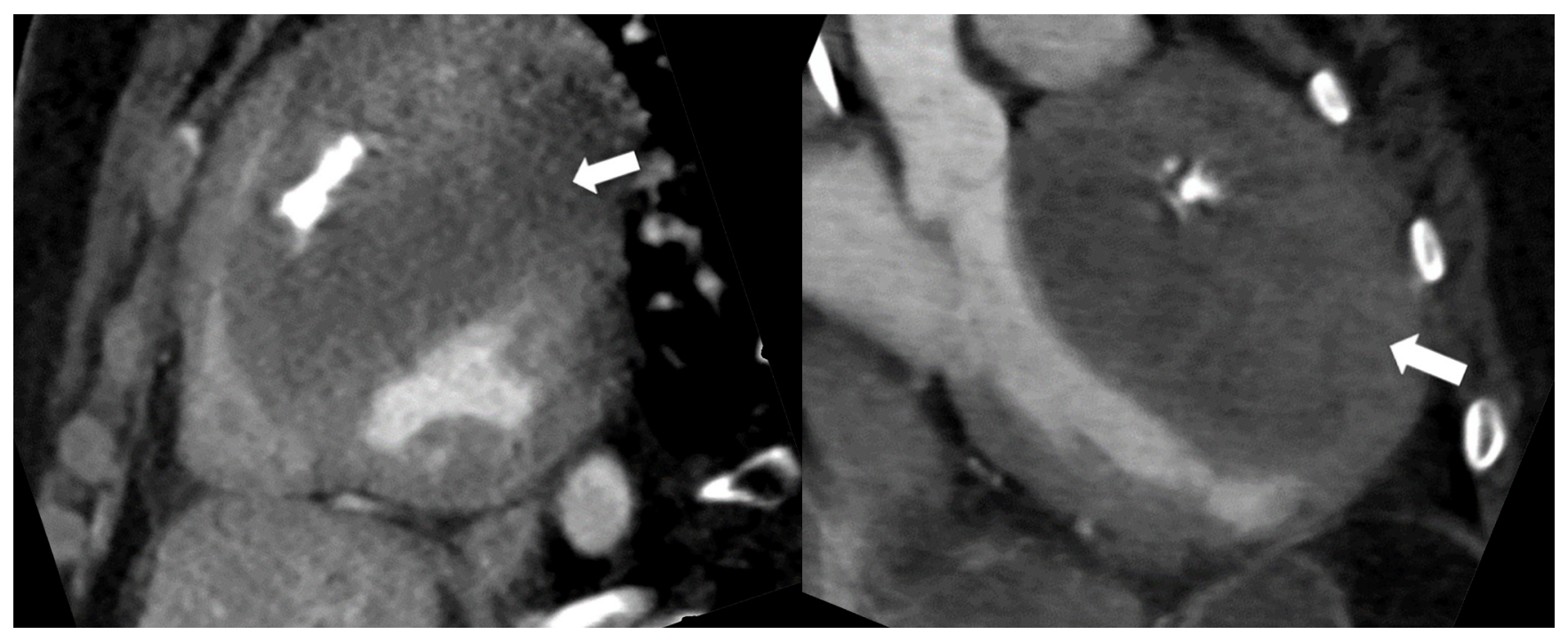

Figure 3. Chest computed tomography in sagittal view showing a mass in left ventricle anteroseptal wall (white arrows).

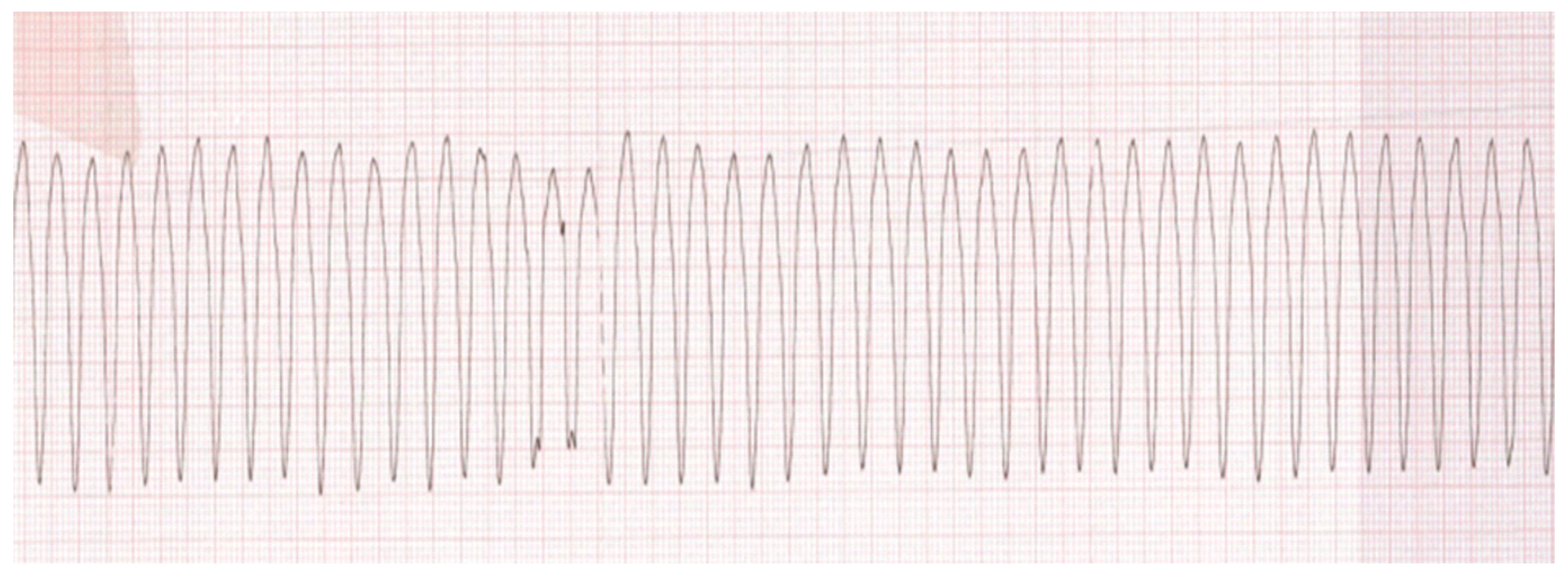

Figure 4. Electrocardiogram showing monomorphic ventricular tachycardia.

(ICD) generator (Visia AF MRI XT VR SureScan; Medtronic, Minneapolis, MN, USA) with a lead (model 6935M-62cm, Medtronic) attached to the right ventricle was inserted (Figure 5). On the 11th day, weaning from mechanical ventilation was initiated. Additionally, the intravenous antiarrhythmic agents were discontinued, and oral amiodarone (10 mg/kg/day) and propranolol ( $0.75 \mathrm{mg} / \mathrm{kg} /$ day) were prescribed. On the $18 \mathrm{th}$ day, in the absence of an episode of ventricular arrhythmia from ICD memory for five days, he was discharged in stable condition with the ICD generator and followed up in the outpatient clinic.

\section{DISCUSSION}

Cardiac fibromas are single solid tumors that commonly in- volve the left ventricular free wall or interventricular septum, although they can be located in any chamber wall [2]. Patients can be asymptomatic or experience cardiovascular complications depending on tumor size and location. Diagnosis is usually established by echocardiography, computed tomography, and magnetic resonance imaging [3]. Two-dimensional Doppler echocardiography is the preferred diagnostic modality for pediatric cardiac tumor evaluation, while magnetic resonance imaging is considered superior in detecting apical tumors and fibromas. Arrhythmias include complete atrioventricular block, ventricular tachycardia, and rarely, supraventricular tachycardia. In a retrospective, single-center review of 25 patients, 16 (64\%) had ventricular tachycardia, and 13 underwent complete or partial tumor resection; ventricular tachycardia was not observed thereafter [4]. 
There is consensus regarding the need for surgical treatment of symptomatic cardiac fibromas [5]. Favorable long-term results after surgical resection have been reported. However, for nonresectable tumors, partial resection, cardiac transplantation, or conservative management have been advised in symptomatic patients. Conversely, surgical resection is recommended for asymptomatic cases, where the risk of sudden death secondary to life-threatening ventricular arrhythmia is increased. Ventricular arrhythmias refractory to antiarrhythmic agents are indications for surgical resection [6]. However, in some cases, the use of ICDs for persistent arrhythmias due to

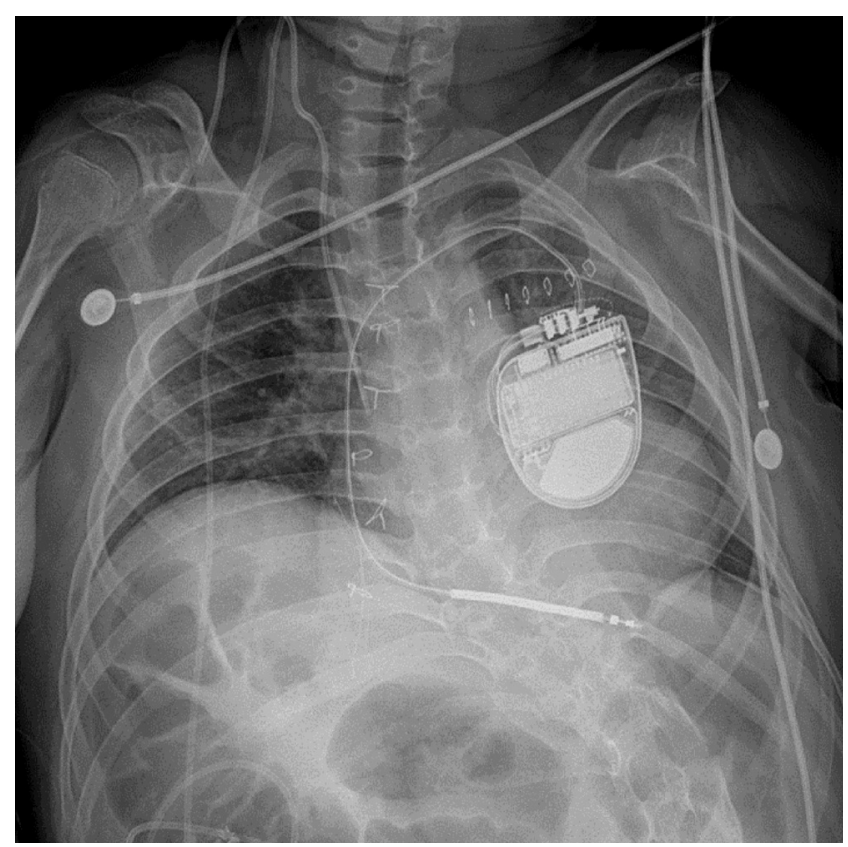

Figure 5. Chest radiograph showing placement of an implantable cardioverter defibrillator system. non-resectable cardiac tumors has been reported.

Thøgersen et al. [7] have reported a case of a 4-month-old infant with multiple cardiac rhabdomyomas and a life-threatening ventricular arrhythmia that was refractory to antiarrhythmic agents; the patient was treated with an ICD. Ventricular arrhythmia did not occur during the 12-month follow-up period. Chockalingam et al. [8] have described a case of an 8-month-old infant with multiple cardiac rhabdomyomas and life-threatening ventricular arrhythmia despite medical treatment; the patient was treated with a subcutaneous ICD. Arrhythmia was not reported during a 2-year follow-up period. Park and Pollock [9] have described a case of a seven-month-old infant with an LV fibroma and recurrent ventricular arrhythmia despite two repeated surgical resections; the patient was treated with an epicardial ICD and later underwent cardiac transplant at 18 months of age (Table 1).

In the current case, complete tumor resection was not performed at the initial surgery because the tumor had diffused into the LV anteroseptal wall. The remaining cardiac fibroma induced life-threatening, drug-resistant ventricular arrhythmia. Hence, an ICD was inserted to prevent sudden death. Earlier such treatment could have resulted in a better outcome, which is why we present this case for referral in future cases. ICDs are increasingly being used in the pediatric population to overcome life-threatening ventricular arrhythmia. Complications such as infection, lead dislodgement and fracture, and a relatively higher rate of inappropriate shock than observed in adults have been reported.

However, to prevent sudden cardiac death, ICD therapy is usually recommended in patients with cardiac tumors and drugresistant ventricular arrhythmias. Furthermore, an ICD can serve as a transitional treatment prior to a cardiac transplant [10].

Table 1. Case reports of implantable cardioverter defibrillator treatment for left ventricular fibroma-induced ventricular arrhythmia in a child

\begin{tabular}{lccc}
\hline Variable & Thøgersen et al. (2001) [7] & Chockalingam et al. (2009) [8] & Park and Pollock (1999) [9] \\
\hline $\begin{array}{lcc}\text { Sex } \\
\text { Symptom at onset }\end{array}$ & Male & Female & Male \\
Age at symptom onset and diagnosis & Cardiac arrest due to VF & Cardiac arrest due to VF & Cardiac arrest due to VF \\
Age at ICD implantation & $9 \mathrm{wk}$ & 40 day & $7 \mathrm{mo}$ \\
Oral medicine & $4 \mathrm{mo}$ & $8 \mathrm{mo}$ (first ICD) \\
Surgical resection & Unknown & Amiodarone and flecainide & 18 mo (second ICD due to mediastinitis) \\
Follow-up after ICD implantation & No & No & Amiodarone \\
Cardiac transplant & $1 \mathrm{yr}$ & $2 \mathrm{yr}$ & Fail (2 trials) \\
\hline
\end{tabular}

VF: ventricular fibrillation; ICD: implantable cardioverter defibrillator. 


\section{CONFLICT OF INTEREST}

No potential conflict of interest relevant to this article was reported.

\section{ORCID}

In Su Choi

https://orcid.org/0000-0001-6428-3036

Hyung Ki Jeong https://orcid.org/0000-0001-5749-9525

Hyung Wook Park https://orcid.org/0000-0002-9630-0467

Yi-Seul Kim

\section{AUTHOR CONTRIBUTIONS}

Conceptualization: YSK. Data curation: ISC. Formal analysis, Methodology, \& Project administration: YSK. Visualization: all authors. Writing-original draft: ISC, YSK. Writing-review \& editing: HKJ, HWP, YSK.

\section{REFERENCES}

1. Elderkin RA, Radford DJ. Primary cardiac tumours in a paediatric population. J Paediatr Child Health 2002;38:173-7.

2. Parmley LF, Salley RK, Williams JP, Head GB 3rd. The clinical spectrum of cardiac fibroma with diagnostic and surgical considerations: noninvasive imaging enhances management. Ann Thorac Surg. 1988;45:455-65.

3. Bortolotti U, Maraglino G, Rubino M, Santini F, Mazzucco A,

Milano A, et al. Surgical excision of intracardiac myxomas: a 20-year follow-up. Ann Thorac Surg 1990;49:449-53.

4. Allen HD, Driscoll DJ, Shaddy RE, Feltes TF. Moss \& Adams' heart disease in infants, children, and adolescents: including the fetus and young adult. 9th ed. Philadelphia, PA: Lippincott Williams \& Wilkins; 2016.

5. Mühler EG, Kienast W, Turniski-Harder V, von Bernuth G. Arrhythmias in infants and children with primary cardiac tumours. Eur Heart J 1994;15:915-21.

6. Cho JM, Danielson GK, Puga FJ, Dearani JA, McGregor CG, Tazelaar HD, et al. Surgical resection of ventricular cardiac fibromas: early and late results. Ann Thorac Surg 2003;76:192934 .

7. Thøgersen AM, Helvind M, Jensen T, Andersen JH, Jacobsen JR, Chen X. Implantable cardioverter defibrillator in a 4-monthold infant with cardiac arrest associated with a vascular heart tumor. Pacing Clin Electrophysiol 2001;24:1699-700.

8. Chockalingam P, Clur SA, Wilde AA, Kuipers I, van Woensel J, Blom NA. Implantable cardioverter defibrillator as a bridge to recovery in an infant with cardiac rhabdomyoma. Eur J Pediatr 2009;168:863-6.

9. Park JK, Pollock ME. Use of an implantable cardioverter defibrillator in an eight-month-old infant with ventricular fibrillation arising from a myocardial fibroma. Pacing Clin Electrophysiol 1999;22(1 Pt 1):138-9.

10. Myers KA, Wong KK, Tipple M, Sanatani S. Benign cardiac tumours, malignant arrhythmias. Can J Cardiol 2010;26:e58-61. 